John Carroll University

Carroll Collected

$4-2018$

\title{
Comment on Amézquita et al. (2017) "Conspicuousness, color resemblance, and toxicity in geographically diverging mimicry: The pan-Amazonian frog Allobates femoralis"
}

Ralph Saporito

John Carroll University, rsaporito@jcu.edu

Taran Grant

University of Sao Paulo, Brazil

Follow this and additional works at: https://collected.jcu.edu/fac_bib_2018

Part of the Biology Commons

\section{Recommended Citation}

Saporito, Ralph and Grant, Taran, "Comment on Amézquita et al. (2017) "Conspicuousness, color resemblance, and toxicity in geographically diverging mimicry: The pan-Amazonian frog Allobates femoralis ”" (2018). 2018 Faculty Bibliography. 23.

https://collected.jcu.edu/fac_bib_2018/23 


\title{
Comment on Amézquita et al. (2017) "Conspicuousness, color resemblance, and toxicity in geographically diverging mimicry: The pan-Amazonian frog Allobates femoralis"
}

\begin{abstract}
Amézquita et al. (2017) recently concluded that species of the Allobates femoralis group are toxic to mice at levels equivalent to syntopic alkaloid-containing poison frogs, which they attributed to the presence of alkaloids in skin secretions. However, the chemical composition of skin secretions was not analyzed, and here we present additional data supporting the absence of alkaloids in skin secretions of the Allobates femoralis group. Instead, we suggest the observed toxicity was caused by the anesthetic benzocaine, which was applied to the buccal cavity to euthanize frogs prior to skin removal. We show that orally administered benzocaine is rapidly incorporated into the skin of species that sequester and do not sequester alkaloids, which casts doubt on the conclusion that Allobates femoralis group skin secretions are toxic and makes the results of experiments with alkaloid-containing species of Adelphobates and Ameerega uninterpretable. To prevent experimental errors and misinterpretations in studies of amphibian chemical defense, we encourage researchers to test the chemical composition of samples prior to experimentation, include all necessary controls to detect false positives, conduct small pilot studies for new methods, and consider the limitations of particular methods and their ability to address the intended research questions.
\end{abstract}

KEY WORDS: Alkaloid, anura, benzocaine, chemical defense, poison frogs, toxicity.

Brightly colored poison frogs of the family Dendrobatidae secrete alkaloid-based chemical defenses that are sequestered from dietary arthropods and provide protection from predators and pathogens (Saporito et al. 2012; Mina et al. 2015). Sequestration as a defensive strategy appears to have evolved independently in four lineages of dendrobatids, with 97 dendrobatid species in 11 genera known or believed (based on coloration and phylogeny) to employ alkaloid-based defenses (Grant et al. 2006, 2017; Saporito et al. 2012; Santos et al. 2014). No species of the sister group of Dendrobatidae, Aromobatidae, is known to possess alkaloidbased chemical defenses (Grant et al. 2006, 2017), despite the astonishing resemblance in coloration and skin texture of Allobates femoralis group species to several alkaloid-containing species of the dendrobatid genus Ameerega. Daly et al. (1987: 1078) reported a trace amount of the 5,8-disubstituted indolizidine 181B from Allobates femoralis in Napo, Ecuador but detected no alkaloids in frogs from five other localities (Lago Agrio, Ecuador; Putumayo, Colombia; Pebas, Peru; Rio Llullapichis, Peru; and Cataracts, Surinam), and J.W. Daly clarified that the Napo sample actually contained a "trace, trace" amount (pers. comm. to T.G. and R.A.S.) that should not be treated "as evidence for significant ability for accumulation of alkaloids in this species" (in litt. to T.G., February 2, 2000). We further confirm the absence of lipophilic alkaloids in samples of Allobates femoralis from 


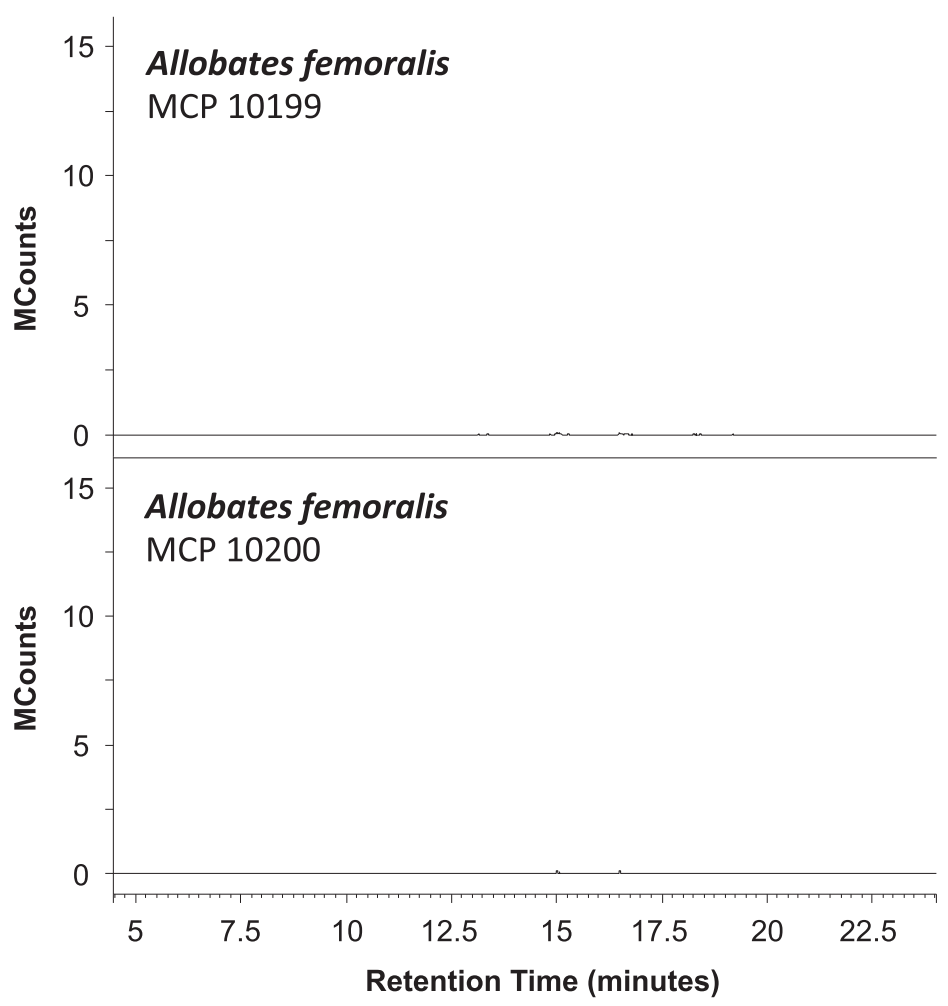

Figure 1. Gas chromatography (GC) trace of two individual Allobates femoralis from Reserva Extrativista Riozinho Liberdade, Brazil. No alkaloids were detected in either individual. Note: the unlabeled peaks represent fatty acids. MCounts (Mega Counts) is a measure of the total ion count (TIC) for each compound present in the GC trace. Retention time represents the time interval between sample injection and the maximum peak height for each compound in the GC trace. See Supplementary Information for experimental methods.

Reserva Extrativista Riozinho Liberdade, Brazil (Fig. 1), although samples from other populations and/or feeding experiments could lead to different results. Similarly, Darst et al. (2005: 59) characterized Allobates zaparo, also part of the Allobates femoralis group, as possessing "trace $(\mathrm{T})$, possibly very small amount of alkaloids," but their assessment of skin secretions used thin layer chromatography and the identity of the supposed alkaloids was not determined. Furthermore, injected skin secretions of both Allobates femoralis and Allobates zaparo have been found to be nontoxic to the house mouse, Mus musculus (Darst and Cummings 2006; Darst et al. 2006). Consequently, species of the Allobates femoralis group are believed to lack skin alkaloids and be Batesian mimics of sympatric species of alkaloid-containing species of the genus Ameerega (Darst and Cummings 2006; Darst et al. 2006).

Contrary to those previous findings, Amézquita et al. (2017) recently concluded that Allobates femoralis group skin secretions are toxic, using behavioral assays with mice, at levels equivalent to syntopic alkaloid-containing dendrobatids in the genera Adelphobates and Ameerega, suggesting they are Müllerian, not Batesian, mimics. Moreover, they attributed the toxicity of Allobates femoralis group species to the presence of alkaloids in the frog skin secretions. However, critical oversights in their experimental procedures call those conclusions into question.

First, Amézquita et al. (2017) did not analyze the chemical composition of the skin secretions they studied, so their conclusion that the inferred toxicity of samples was due to alkaloids is unfounded. Second, although not specified in Materials and Methods, Amézquita et al. (2017) euthanized frogs by buccal application of an undetermined quantity of $20 \%$ benzocaine in gel form (Benzotop, DFL Indústria e Comércio, Rio de Janeiro, RJ, Brazil; A.P. Lima, in litt. to T.G., March 23, 2017) prior to skin removal. Benzocaine (10-20\% solution) is a synthetic anesthetic commonly used for euthanizing frogs (McDiarmid 1994), typically by direct application to the skin where it is quickly absorbed; however, this poses a significant problem when studying the physiological and/or behavioral effects of skin secretions on other organisms. At the molecular level, frog alkaloids and benzocaine share similar modes of action: frog alkaloids interfere with various subtypes of nicotinic receptors and a diversity of ion channels (e.g., $\mathrm{Na}^{+}, \mathrm{K}^{+}, \mathrm{Ca}^{2+}$ channels; Daly et al. 1999, 2005; Santos et al. 2016), and benzocaine interferes with $\mathrm{Na}^{+}$ channels (Schneider and Dubois 1986; Wang and Wang 1994; Quan et al. 1996). Also, benzocaine is known to inhibit locomotor 
activity in mice (Reith et al. 1985) and cause methemoglobinemia (Davis et al. 1993), the symptoms of which vary in humans from cyanosis, dizziness, lethargy, and syncope to seizures, arrhythmias, shock, and even death, depending on methemoglobin concentration (Rodriguez et al. 1994). In nonhuman animals, even a low concentration of methemoglobin (10\%) "results in a direct decrement in $\mathrm{O}_{2}$-carrying capacity of erythrocytes, which can affect performance studies" (Davis et al. 1993: 1325). In an attempt to circumvent this problem, Amézquita et al. (2017) applied benzocaine to the buccal cavity of frogs, assuming this would prevent benzocaine from contaminating the skin secretions.

Unfortunately, orally administered benzocaine accumulates rapidly in the highly vascularized skin of frogs and is present in skin extracts following euthanasia. On the basis of new data presented below, oral administration of lethal doses of benzocaine results in the accumulation of large amounts of benzocaine in euthanized individuals of both alkaloid-sequestering and nonalkaloid-sequestering frogs (Fig. 2; for chemical profiles of individuals of these poison frog species euthanized by other means, see Daly et al. 1987, Jeckel et al. 2015a,b). In the bufonid poison frog Melanophryniscus moreirae, the amount of benzocaine in the skin following oral administration of $10 \mu \mathrm{L}$ of liquid Orajel ${ }^{\circledR}$ containing 20\% benzocaine (Church \& Dwight Co., Inc., Ewing, New Jersey) was equivalent to almost $50 \%$ of the total amount of the naturally occurring chemical defenses (Fig. 2A). The large quantity of benzocaine was greater than the amount of bufotenine and almost as great as the amount of pumiliotoxin $267 \mathrm{C}$, the most abundant skin alkaloid in this species (Jeckel et al. 2015a). In identical experiments with a captive bred individual of the dendrobatid poison frog Dendrobates auratus and the nonalkaloid sequestering ranid frog Lithobates clamitans, benzocaine also rapidly accumulated in the skin in large amounts (Fig. 2B and C). As such, following the procedure of Amézquita et al. (2017), skin samples that originally contained and did not contain lipophilic alkaloids would all contain large amounts of benzocaine. Although a detailed understanding of the pharmacokinetics of benzocaine in amphibians is lacking, in fish benzocaine is rapidly distributed to highly perfused tissues prior to elimination (Meinertz et al. 1999), and we suspect the same occurs in amphibians. When used as an agent for euthanasia, benzocaine elimination does not proceed, which might explain its presence in such large amounts in the skins of euthanized frogs.

The fact that large amounts of benzocaine accumulate in the skin following oral administration of a lethal dose of that anesthetic casts doubt on Amézquita et al.'s (2017) conclusions about frog toxicity. Injection of Allobates femoralis group skin extracts lacking naturally occurring skin alkaloids but containing large amounts of benzocaine are expected to elicit similar responses to those reported by Amézquita et al. (2017), with variation in the extent of responses caused by differences in the unquantified amounts of benzocaine used to euthanize frogs. Further, the occurrence of large and variable amounts of benzocaine in skins of alkaloid-containing species of Adelphobates and Ameerega makes the results of experiments with those species uninterpretable, since responses would vary as a function of both the well-documented individual variation in naturally occurring skin alkaloids (Saporito et al. 2012) and the different amounts of benzocaine used to euthanize frogs.

Despite our criticisms, studies like that of Amézquita et al. (2017) aiming to investigate the relationship between geographic variation in coloration and chemical defenses are essential to understand the ecology and evolution of chemical defense in anurans, and it is not our aim to discourage efforts in this area. To the contrary, we hope this critique will help future studies to take the necessary steps to ensure the integrity of their results. To that end, we offer the following general guidelines. First, it is imperative that the chemical composition of samples be tested prior to any subsequent experimentation. We have shown that oral administration of lethal doses of benzocaine result in the accumulation of large amounts of the anesthetic in the skin of euthanized frogs, and other anesthetics commonly used to euthanize amphibians, including tricaine methanesulfonate (MS-222) and lidocaine, are likely to behave similarly. In contrast, euthanasia by immersion in ethanol would result in the extraction of alkaloids from skin, which would also alter the results of subsequent experimentation. Chemical analysis of skins would have allowed Amézquita et al. (2017) to detect benzocaine in their samples and either choose a different method of euthanasia (e.g., Shine et al. 2015; Lillywhite et al. 2017) or include benzocaine control injections in their procedures. Second, studies must include all necessary controls to detect false positives. Amézquita et al. (2017) appropriately injected saline solution into mice as a negative control, but the inclusion of a species confirmed to lack alkaloids (e.g., a nonpoison frog) would have enabled them to determine if some other component of their experimental treatment was confounding their results. Third, we strongly recommend conducting small pilot studies, especially when experiments require individuals to be euthanized. A small pilot study that tested chemical compositions and included all necessary controls would have allowed Amézquita et al. (2017) to correct their procedures before euthanizing the 95 frogs included in their study.

Finally, the limitations of particular research methods must be considered. For example, lipophilic alkaloids are not the only sources of chemical defenses in anurans, so it is possible for skin secretions of species that lack lipophilic alkaloids to elicit positive toxicity responses. All amphibians possess granular glands that presumably secrete defensive chemicals (Toledo and Jared 1995), yet fewer than 200 species are known or believed to secrete alkaloids. Even among dendrobatids, two species that lack lipophilic alkaloids possess water-soluble toxins (Daly et al. 1994; 


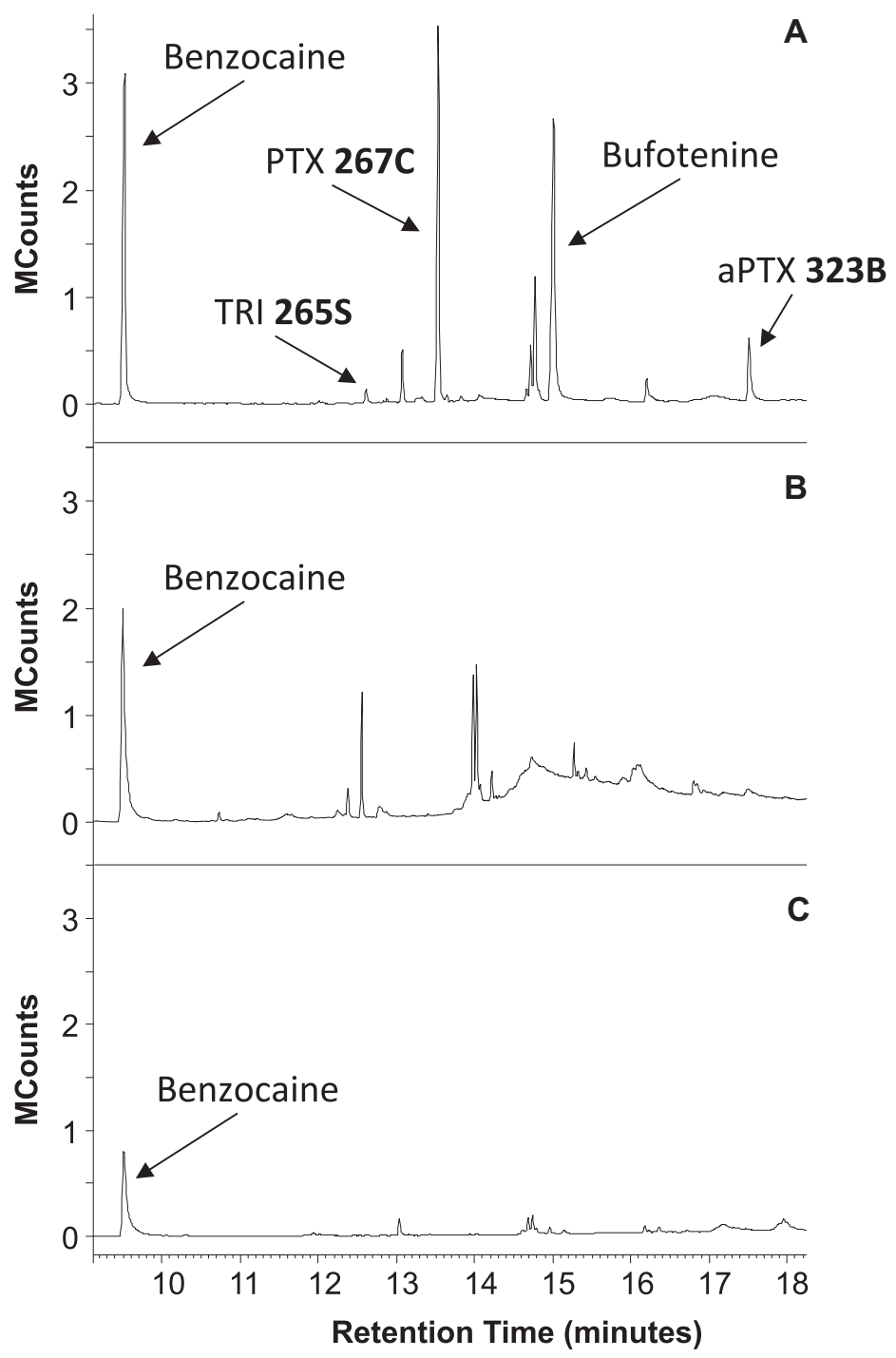

Figure 2. (A) Gas chromatography (GC) trace of individual Melanophryniscus moreirae skin/methanol extract. Alkaloid classes: tricyclic (Tri), pumiliotoxin (PTX), and allopumiliotoxin (aPTX). The unlabeled peaks represent fatty acids and fatty acid methyl esters (FAMES); (B) GC trace of individual Dendrobates auratus skin/methanol extract; (C) GC trace of individual Lithobates clamitans skin/methanol extract. The unlabeled peaks represent fatty acids. MCounts (Mega Counts) is a measure of the total ion count (TIC) for each compound present in the GC trace. Retention time represents the time interval between sample injection and the maximum peak height for each compound in the GC trace. See Supplementary Information for experimental methods.

Grant 2007), and amphibians generally are known to secrete biogenic amines, bufadienolides, peptides and proteins, and several classes of alkaloids (Erspamer 1994). Similarly, chemical defenses evolved in relation to naturally occurring pathogens and predators, not the mouse. Mice are the standard test subjects in many toxicity studies because they are believed to be a good proxy for humans, but, given that mice are not considered a potential natural predator or closely related to any potential predator of poison frogs and defensive secretions are ingested, not injected, the ecological or evolutionary relevance of the effects of these injections on mice is unclear (for further discussion, see Bolton et al. 2017; Weldon 2017). That is, injection of skin secretions might be highly toxic to mice while ingestion might have little or no effect on potential avian, snake, or arthropod predators, or they might have no effect on mice, but be extremely effective at inhibiting pathogens across a broad spectrum. The reliance on particular and perhaps inappropriate species for bioassays of toxicity can be avoided by instead focusing on the chemical composition of secretions, but care in interpretation is required here as well, as such studies provide no evidence regarding the functional effects of secretions on potential pathogens and predators. Consequently, studies on the alkaloid composition of poison frogs cannot say 
whether a frog with one set of alkaloids is more or less defended ("toxic") than another frog with a different set of alkaloids, even if the total number or quantity of alkaloids differs greatly.

Chemical defense is a fundamental aspect of the biology of amphibians that has shaped their evolution and governs their ecology, and interdisciplinary studies that focus on chemical defense are essential to construct a complete understanding of this clade. Nevertheless, it is imperative that researchers adequately consider both the biology and the chemistry to avoid mistakes that undermine or invalidate their conclusions.

\section{AUTHOR CONTRIBUTIONS}

R.A.S. and T.G. contributed equally to the writing of this manuscript.

\section{ACKNOWLEDGMENT}

We thank M.A. Donnelly, M.R. Parker, A.H. Savitzky, and P.J. Weldon for valuable comments that improved this manuscript. Tests of benzocaine accumulation in Melanophryniscus moreirae were conducted in collaboration with A.M. Jeckel. We are grateful to A.P. Lima for providing information on the method employed to euthanize frogs for the study by Amézquita et al. (2017). Brazilian scientific collecting permits were issued by the Instituto Chico Mendes de Conservação da Biodiversidade (SISBIO licenses 12178-2, 13173-1, 13173-2, and 41014-1) and Allobates femoralis samples were exported under permit 17BR025048/DF. U.S. scientific collecting permits were issued by the Ohio Department of Natural Resources (ODNR permit 18-131). Our research was supported by the Conselho Nacional de Desenvolvimento Científico e Tecnológico (CNPq Proc. 305234/2014-5) and Fundação de Amparo à Pesquisa do Estado de São Paulo (FAPESP Proc. 2012/10000-5).

The authors have no conflict of interest to declare.

\section{LITERATURE CITED}

Amézquita, A., Ó. Ramos, M. C. González, C. Rodríguez, I. Medina, P. I. Simões, and A. P. Lima. 2017. Conspicuousness, color resemblance, and toxicity in geographically diverging mimicry: the pan-Amazonian frog Allobates femoralis. Evolution 71:1039-1050.

Bolton, S. K., K. Dickerson, and R. A. Saporito. 2017. Variable alkaloid defenses in the dendrobatid poison frog Oophaga pumilio are perceived as differences in palatability to arthropods. J. Chem. Ecol. 43:273-289.

Daly, J. W., T. F. Spande, and H. M. Garraffo. 2005. Alkaloids from amphibian skin: a tabulation of over eight hundred compounds. J. Nat. Prod. 68:1556-1575.

Daly, J. W., F. Gusovsky, C. W. Myers, M. Yotsu-Yamashita, and T. Yasumoto. 1994. First occurrence of tetrodotoxin in a dendrobatid frog (Colostethus inguinalis), with further reports for the bufonid genus Atelopus. Toxicon 32:279-285.

Daly, J. W., C. W. Myers, and N. Whittaker. 1987. Further classification of skin alkaloids from neotropical poison frogs (Dendrobatidae), with a general survey of toxic/noxious substances in the Amphibia. Toxicon 25:1023-1095.

Darst, C. R., and M. E. Cummings. 2006. Predator learning favours mimicry of a less-toxic model in poison frogs. Nature 440:208-211.

Darst, C. R., M. E. Cummings, and D. C. Cannatella. 2006. A mechanism for diversity in warning signals: conspicuousness versus toxicity in poison frogs. Proc. Natl. Acad. Sci. USA 103:5852-5857.
Darst, C. R., P. A. Menéndez-Guerrero, L. A. Coloma, and D. C. Cannatella. 2005. Evolution of dietary specialization and chemical defense in poison frogs (Dendrobatidae): a comparative analysis. Am. Nat. 165:56-69.

Daly, J. W., H. M. Garraffo, and T. F. Spande. 1999. Alkaloids from amphibian skins. Pp. 1-161 in S. W. Pelletier, ed. Alkaloids: Chemical and biological perspectives. Pergamon, New York.

Davis, J. A., R. E. Greenfield, and T. G. Brewer. 1993. Benzocaine-induced methemoglobinemia attributed to topical application of the anesthetic in several laboratory animal species. Am. J. Vet. Res. 54:1322-1326.

Erspamer, V. 1994. Bioactive secretions of the amphibian integument. Pp. 178-350 in H. Heatwole and G. T. Barthalmus, eds. Amphibian biology. The Integument. Surrey Beatty \& Sons Pty., Ltd. Chipping Norton, U.K, Chipping.

Grant, T. 2007. A new, toxic species of Colostethus (Anura: Dendrobatidae) from the Cordillera Central of Colombia. Zootaxa 1555:39-51.

Grant, T., D. R. Frost, J. P. Caldwell, R. Gagliardo, C. F. B. Haddad, P. J. R. Kok, B. D. Means, B. P. Noonan, W. E. Schargel, and W. C. Wheeler. 2006. Phylogenetic systematics of dart-poison frogs and their relatives (Anura: Athesphatanura: Dendrobatidae). Bull. Am. Mus. Nat. Hist. 299:1-262.

Grant, T., M. Rada, M. Anganoy-Criollo, A. Batista, P. H. Dias, A. M. Jeckel, D. J. Machado, and J. V. Rueda-Almonacid. 2017. Phylogenetic systematics of dart-poison frogs and their relatives revisited (Anura: Dendrobatoidea). South Am. J. Herpetol. 12:S1-S90.

Jeckel, A. M., T. Grant, and R. A. Saporito. 2015a. Sequestered and synthesized chemical defenses in the poison frog Melanophryniscus moreirae. J. Chem. Ecol. 41:505-512.

Jeckel, A. M., R. A. Saporito, and T. Grant. 2015b. The relationship between poison frog chemical defenses and age, body size, and sex. Front. Zool. $12: 27-27$.

Lillywhite, H. B., R. Shine, E. Jacobson, D. F. DeNardo, M. S. Gordon, C. A. Navas, T. Wang, R. S. Seymour, K. B. Storey, H. Heatwole, et al. 2017. Anesthesia and euthanasia of amphibians and reptiles used in scientific research: should hypothermia and freezing be prohibited? Bioscience 67:53-61.

Meinertz, J. R., G. R. Stehly, and W. H. Gingerich. 1999. Metabolism, elimination, and pharmacokinetics of the fish anesthetic benzocaine. Pp. 189-200 in Xenobiotics in fish. Springer, Berlin, Germany.

Mina, A. E., A. K. Ponti, N. L. Woodcraft, E. E. Johnson, and R. A. Saporito. 2015. Variation in alkaloid-based microbial defenses of the dendrobatid poison frog Oophaga pumilio. Chemoecology 25:169-178.

McDiarmid, R. W. 1994. Preparing amphibians as scientific specimens. Pp. 289-297 in W. R. Heyer, M. A. Donnelly, R. W. McDiarmid, L.-A. C. Hayek, and M. S. Foster, eds. Measuring and monitoring biological diversity: standard methods for amphibians. Smithsonian Institution Press, Washington.

Quan, C., W. M. Mok, and G. K. Wang. 1996. Use-dependent inhibition of $\mathrm{Na}^{+}$currents by benzocaine homologs. Biophys. J. 70:194-201.

Reith, M. E. A., B. E. Meisler, and A. Lajtha. 1985. Locomotor effects of cocaine, cocaine cogeners, and local anesthetics in mice. Pharmacol. Biochem. Behav. 23:831-836.

Rodriguez, L. F., L. M. Smolik, and A. J. Zbehlik. 1994. Benzocaine-induced methemoglobinemia: report of a severe reaction and review of the literature. Ann. Pharmacother. 28:643-649.

Saporito, R. A., M. A. Donnelly, T. F. Spande, and H. M. Garraffo. 2012. A review of chemical ecology in poison frogs. Chemoecology 22:159-168.

Santos, J. C., M. Baquero, C. Barrio-Amoros, L. A. Coloma, L. K. Erdtmann, A. P. Lima, and D. C. Cannatella. 2014. Aposematism increases acoustic diversification and speciation in poison frogs. Proc. R Soc. B Biol. Sci. 281:20141761.

Santos, J. C., R. D. Tarvin, L. A. O'Connell. 2016. A review of chemical defense in poison frogs (Dendrobatidae): ecology, pharamacokinetics, 
and autoresistance. Pp. 305-337 in B. A. Schulte, T. E. Goodwin, and M. H. Ferkin, eds. Chemical signals in vertebrates 13. Springer International Publishing, Switzerland.

Schneider, M. F., and J. M. Dubois. 1986. Effects of benzocaine on the kinetics of normal and batrachotoxin-modified $\mathrm{Na}$ channels in frog node of Ranvier. Biophys. J. 50:523-530.

Shine, R., J. Amiel, A. J. Munn, M. Stewart, A. L. Vyssotski, and J. A. Lesku. 2015. Is "cooling then freezing" a humane way to kill amphibians and reptiles? Biol. Open 4:760-763.
Toledo, R. C., and C. Jared. 1995. Cutaneous granular glands and amphibian venoms. Comp. Biochem. Physiol. Part A Physiol. 111:1-29.

Wang, G. K., and S. Y. Wang. 1994. Binding of benzocaine in batrachotoxinmodified Na+ channels. State-dependent interactions. J. Gen. Physiol. 103:501-518.

Weldon, P. J. 2017. Poison frogs, defensive alkaloids, and sleepless mice: critique of a toxicity bioassay. Chemoecology 27:123-126. 